\title{
Integrated TRMM Data and Standardized Precipitation Index to Monitor the Meteorological Drought
}

\author{
Zaidoon T. Abdulrazzaq ${ }^{a *}$, Raghad H. Hasan ${ }^{\text {b }}$ Nadia A. Aziz ${ }^{\text {a }}$ \\ ${ }^{a}$ Ministry of Science and Technology, Directorate of Space and Communications, Al Jadriya, Baghdad, Iraq. \\ ${ }^{b}$ College of Engineering, University of Baghdad, Baghdad, Iraq.
}

Received 26 March 2019; Accepted 15 June 2019

\begin{abstract}
Droughts are a major problem in Iraq especially in the Arid and Semi-Arid Lands where they are frequent and causes a great deal of suffering and loss. Drought monitoring and forecasting requires extensive climate and meteorological data which is usually largely missing in developing countries or not available in the required spatial and temporal resolutions. In this study, the drought categories were defined for the years 2000, 2005, 2010, 2015 and 2017 using the TRMM data to map the spatiotemporal meteorological drought, and the Standardized Precipitation Index (SPI) to analyze the meteorological drought at 11 stations located in Western Iraq. The SPI analyses were performed on 12-month datasets for five years. The results showed that the northeast region has the higher rainfall indices and the southwest region has the lowest rainfall. An analysis of the drought and rain conditions showed that the quantity of extreme drought events was higher than that expected in the study area, especially in the south and southwest areas. Therefore, an alternate classification is proposed to describe the drought, which spatially classifies the drought type as mild, moderate, severe and extreme. In conclusion, the integration between TRMM data SPI data proved to be an effective tool to map the spatial distribution and drought assessment in the study area.
\end{abstract}

Keywords: Meteorological Drought; GIS; Remote Sensing; TRMM; SPI.

\section{Introduction}

Drought is one of the natural environmental risks occurring due to prolonged water scarcity. This phenomenon could be resulted from low rate or uneven precipitation distribution, inadequacy of water quantity required or the combination of these causes. Along with the increase of world's population, climate change, forest destructions and desertification, the problem of drought was developed, and by the time, it has eventually reached to the proportions that pose a threat to the society, environment and countries. Nowadays, many places on Earth (especially Arid and Semi-Arid areas) face desertification risk due to severe drought. Droughts could be classified into three types, meteorological, hydrological and agricultural. When a meteorological drought occurs in an area, the agricultural and hydrological drought follows. When deficits in precipitation in an area occur with an actual rainfall less than $75 \%$ on the long-term climatological mean, the resulting drought is known as meteorological drought [1].

Precipitation data is considered as an important element of many environmental and hydrological studies such as drought, climate change, desertification and other strategic studies. Mapping the spatiotemporal drought distribution is essential in various aspects as the drought is one of the recognized developmental significant hazards. Drought

* Corresponding author: zaidoon.taha@live.com

http://dx.doi.org/10.28991/cej-2019-03091355

(C) 2019 by the authors. Licensee C.E.J, Tehran, Iran. This article is an open access article distributed under the terms and conditions of the Creative Commons Attribution (CC-BY) license (http://creativecommons.org/licenses/by/4.0/). 
monitoring and forecasting require extensive climate and meteorological data, which is usually largely missing in developing countries or not available in the required spatial and temporal resolutions. Remote Sensing Data provides the opportunity to monitor the drought dynamics in a systematic manner. Satellite-based climate data considered as an option in supplementing ground-based meteorological observations data, with a good spatial and temporal cover [2]. Droughts have a direct negative economic effect on several regional sectors. Hence, it is important to adopt an approach that uses drought indices and rainfall data such as satellite-based rainfall from the Tropical Rainfall Measuring Mission (TRMM). Recently, TRMM data have improved in accuracy and start to provide an alternative data for water resources applications, essentially due to a well-distributed and continuous data [3-5].

One of the potential meteorological drought indices is the Standardized Precipitation Index (SPI), which is easily calculable, needs modest data, independent of the magnitude of mean rainfall and could be comparable over a range of climatic zones. Since precipitation indicates significant variation in the area and time period, it is the main factor in the existence of water in most systems. For this reason, many drought indicators rare based on precipitation conditions [6]. The SPI method has been a common method in drought observation in recent years [7]. Since the only meteorological variable required in this method is precipitation, it is very easy to apply $[8,9]$. Another important advantage is the flexibility when measuring the drought for different times. Moreover, SPI converts precipitation data to a numerical values and used to define the drought categories $[10,11]$. SPI can be also applied for any location by using a transformation of precipitation from a skewed distribution to the normal distribution, which makes it a suitable indicator accepted around the world. SPI is probabilistic in nature which is an advantage that was discussed by Guttaman [7] with its usability in risk and decision analysis over other drought indices. The use of SPI is standardized to time scales i.e. 1, 2, 3, 6, 12 24, 26, 48 months. Wet conditions are stated as positive SPI values, while the negative values represent drought states. Various studies were utilizing SPI to monitor the meteorological drought in Iraq with good results [1215].

Geographic information system (GIS) is the basic platform through which data can be easily stored, its packages of applications were used by specialists in various field especially in the environmental studies, which helps the decisionmaker to take the proper action in solving any problem encountered [16-18]. Remote sensing plays an important role in drought assessment as they provide up-to-date information on spatial and temporal scales. To assess drought conditions in an area, different drought indicator are used. Major drought indicators use parameters such as precipitation, vegetation cover, soil moisture, etc. [19]. The remote sensing community has defined drought specifically as "a period of abnormally dry weather, which affects the vegetation cover" [20]. The classical methods for monitoring of droughts using groundbased data are difficult, exhausting and time-consumptive [21]. Satellite measurements of the biosphere have gained their importance in various aspects of environmental monitoring including drought monitoring. For drought monitoring, assessment and prediction, remote sensing and GIS technologies are capable to cover the earth surface better than traditional techniques. Several new approaches have been invented to extract significant information from past and realtime remotely sensed data in drought studies.

This study aims to define the drought categories for the years 2000, 2005, 2010, 2015 and 2017 using the TRMM data to map the spatiotemporal meteorological drought and SPI to analyze the meteorological drought at 11 stations located in Western Iraq.

\section{Material and Methods}

\subsection{Study Area}

The study area located in Western Iraq between latitudes $31^{\circ}-34^{\circ} 30^{\prime} \mathrm{N}$, and longitudes $38^{\circ} 30^{\prime}-44^{\circ} 30^{\prime} \mathrm{E}$, as shown in Figure 1, with total area of about 104000 square meters. It is considered as a large rocky desert plateau, got the term desert according to the absence of vegetation and lack of rainfall; in addition to its limited sedimentary cover. Numerous geological formations are apparent in the study area, whose ages range from Mesozoic rocks to the Quaternary deposits [22]. The topography of the region is characterized by a gradual increase in elevation to the west reach $987 \mathrm{~m}$ above sea level [23]. The variation in elevation is due to variability in the rocky nature of rocks, constructional structure and climate. 


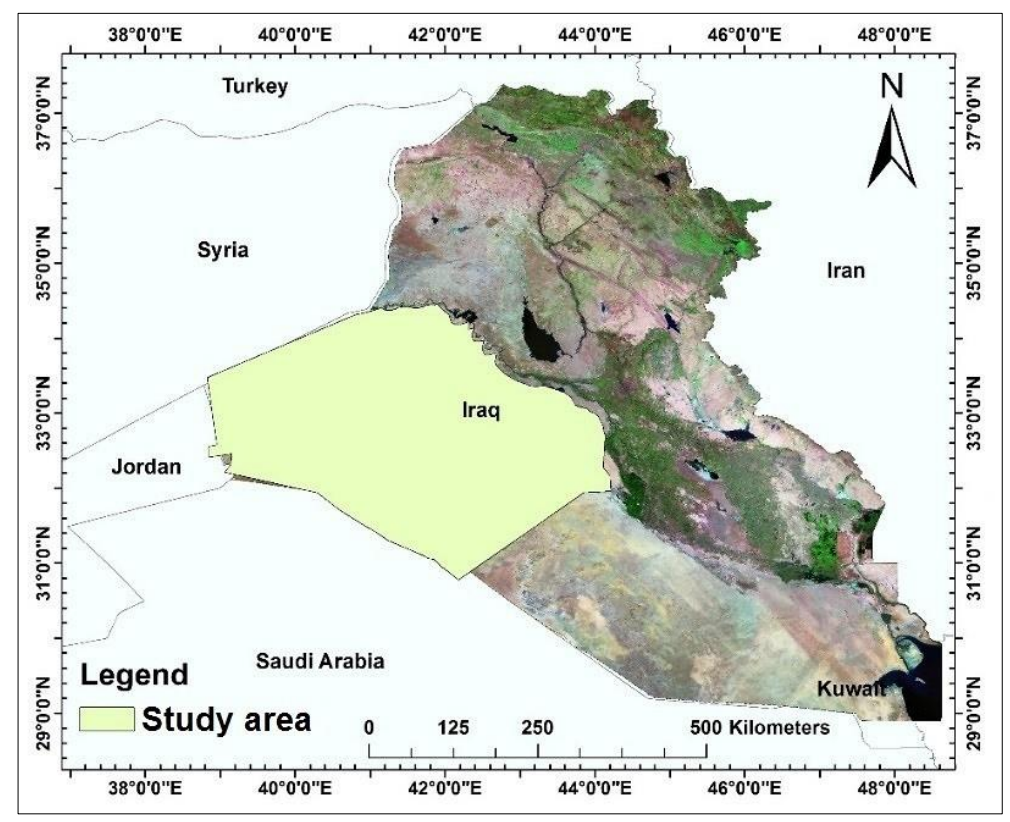

Figure 1. Location of the study area

\subsection{Dataset}

\subsubsection{TRMM Data}

TRMM data is released in two datasets, 3B42 which is resulted by combining passive microwave data from several low orbit satellites with infrared (IR) data gathered by the international constellation of geosynchronous Earth orbit satellites (GEO-IR) and PR active microwave data, this data is available at 3-hour interval. Additionally, 3B43 which is produced by refining 3B42 using several algorithms and ground-based data. The Tropical Rainfall Measuring Mission (TRMM) dataset offers an alternative data source for many applications, essentially because of the well-distributed and continuous database [24]. The annual precipitation for the years $2000,2005,2010,2015$ and 2017 at a $0.25^{\circ} \times 0.25^{\circ}$ spatial resolution, has been downloaded and processed to drive the maps. Annual values were obtained from the TRMM data, and the spatial distribution was estimated using the ordinary Kriging geostatistical interpolation technique. Figure 2 shows the TRMM grid and SPI stations.

\subsubsection{SPI Data}

The SPI-12 data was downloaded and compiled from European Drought Observatory (EDO) website for 11 ground station to determine years of drought versus non-drought conditions using the accumulated seasonal rainfall, while the SPI data of April was collected from the selected years. Figure 3 illustrates the main steps to analysis the drought in this study.

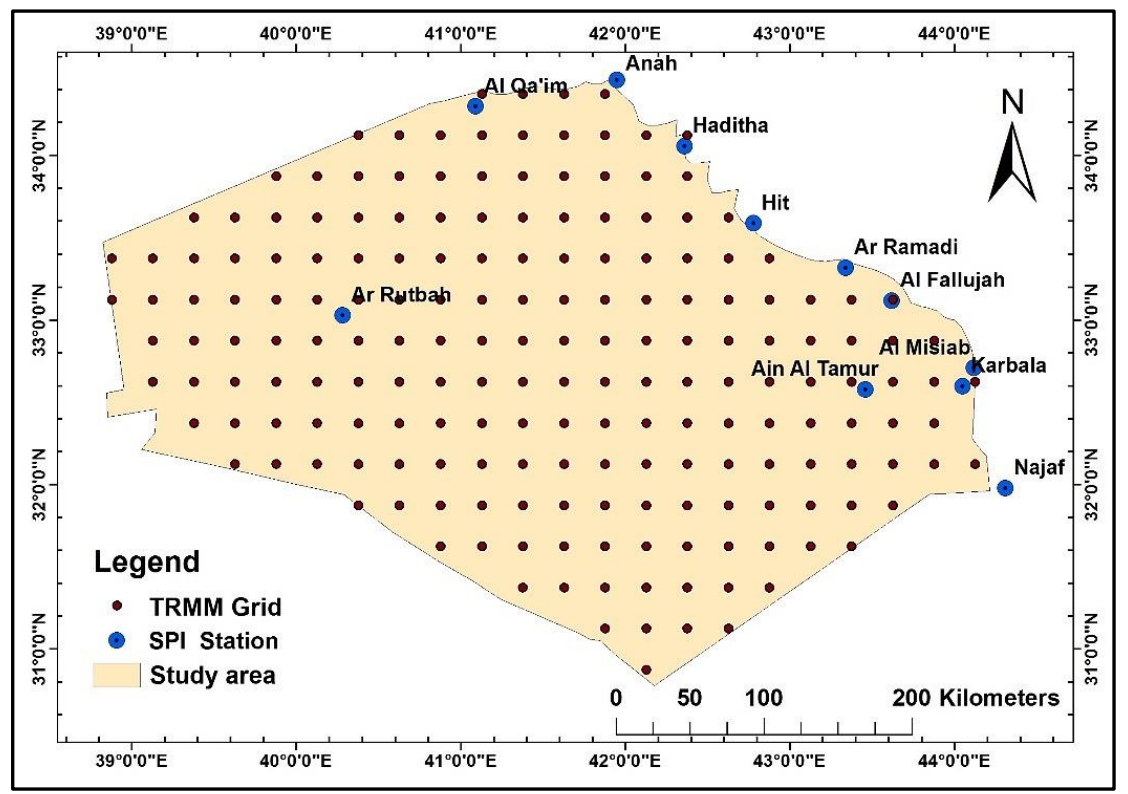

Figure 2. TRMM grid and SPI stations 


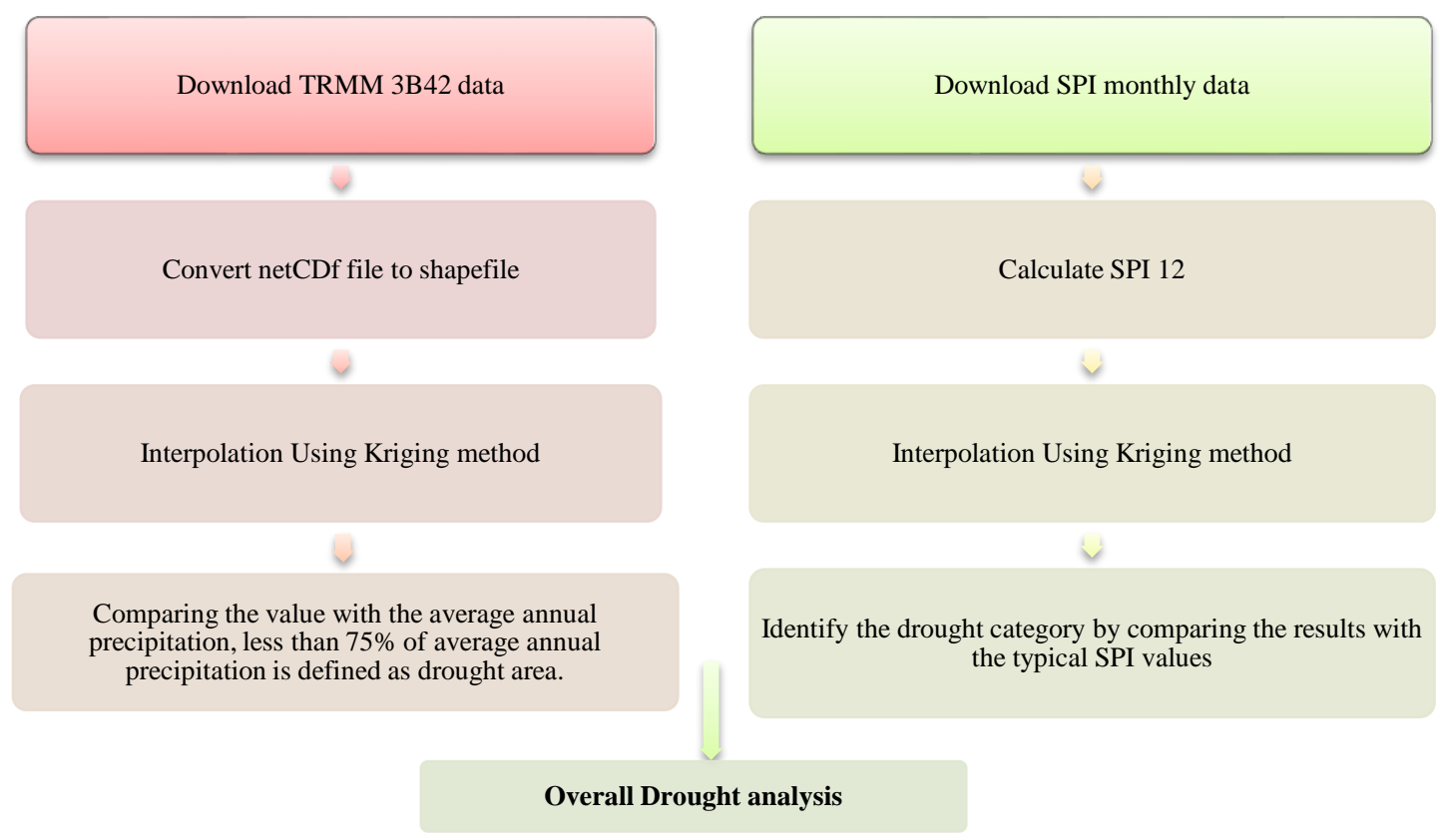

Figure 3. Main steps to analysis the drought

\subsection{SPI}

SPI is one the most commonly adopted drought indices across the world because it is easy to compute and use, suitable for drought comparison across different regions and time spans due to its standardization. Due to its probabilistic nature, SPI is adequate for carrying out drought risk analysis [24]. It was adopted by the World Meteorological Organization as the recommended index to be used all over the world for drought monitoring. This index is calculated by applying a probability distribution on aggregated monthly precipitation series e.g. $\mathrm{k}=3,6,12,24$ months [25]. SPI is a method to assess the drought using the precipitation data. In this index, the negative values indicate drought, while the positive values refer to wet conditions. SPI is a probability index [26] where the difference of significant precipitation (Xi) from average precipitation (Xi mean) is calculated, then division of the difference by the standard deviation $(\sigma)$ of the selected time is done [27]. The SPI grouping values are shown in Table 1. The SPI formula is:

$\mathrm{SPI}=(\mathrm{Xi}-\mathrm{Xi}$ mean $) / \sigma$

Table 1. SPI values Classification [28]

\begin{tabular}{cc}
\hline SPI Value & Drought Category \\
\hline$\geq 2.00$ & Extremely wet \\
$1.50 \_1.99$ & Very wet \\
$1.0 \_1.49$ & Moderately wet \\
$-0.99 \_0.99$ & Near normal \\
$-1.00_{-}-1.49$ & Moderately dry \\
\hline
\end{tabular}

\section{Results and Discussion}

\subsection{SPI and Drought}

Table 2 shows the SPI data for eleven meteorological observation stations in Western Iraq, namely Ain Al Tamur, Al Fallujah, Al Misiab, Al Qa'im, Anah, Ar Ramadi, Ar Rutbah, Haditha, Hit, Karbala and Najaf. The SPI values in the study area ranged from -2.5_0.5, accordingly, the area was classified into two categories; the fourth category (close to the natural) and the fifth (dry type) as shown in Figure 4. Of the 55 SPI values, there were only eight readings within the positive values and 16 readings with values more than -1 . The SPI data was analyzed to show the spatial pattern during these years (Figure 5). The calculated SPI values have been interpolated using the Kriging method to identify the drought zone. 
Table 2. SPI-12 values for the study period

\begin{tabular}{cccccccc}
\hline Station Name & Long. & Lat. & $\mathbf{2 0 0 0}$ & $\mathbf{2 0 0 5}$ & $\mathbf{2 0 1 0}$ & $\mathbf{2 0 1 5}$ & $\mathbf{2 0 1 7}$ \\
\hline Ain Al Tamur & 43.46 & 32.58 & -2.20192 & 0.205 & -1.04758 & -0.98683 & -0.34492 \\
Al Fallujah & 43.62 & 33.12 & -1.799 & 0.504083 & -0.89383 & -1.01233 & -0.38217 \\
Al Misiab & 44.12 & 32.71 & -2.37717 & 0.3645 & -0.68183 & -1.08642 & -0.72533 \\
Al Qa'im & 41.09 & 34.30 & -1.29275 & -0.76775 & -0.96508 & -0.352 & -0.57308 \\
Anah & 41.95 & 34.46 & -1.21117 & -0.83917 & -1.26658 & -0.73808 & -0.11792 \\
Ar Ramadi & 43.34 & 33.32 & -1.799 & 0.504083 & -0.89383 & -1.01233 & -0.38217 \\
Ar Rutbah & 40.28 & 33.03 & -1.67775 & -0.19492 & -0.51425 & 0.105 & -0.7795 \\
Haditha & 42.36 & 34.06 & -1.19108 & -0.82908 & -1.2835 & -0.76017 & -0.16875 \\
Hit & 42.78 & 33.59 & -1.799 & 0.504083 & -0.89383 & -1.01233 & -0.38217 \\
Karbala & 44.05 & 32.60 & -2.37717 & 0.3645 & -0.68183 & -1.08642 & -0.72533 \\
Najaf & 44.31 & 31.98 & -2.37717 & 0.3645 & -0.68183 & -1.08642 & -0.72533 \\
\hline
\end{tabular}

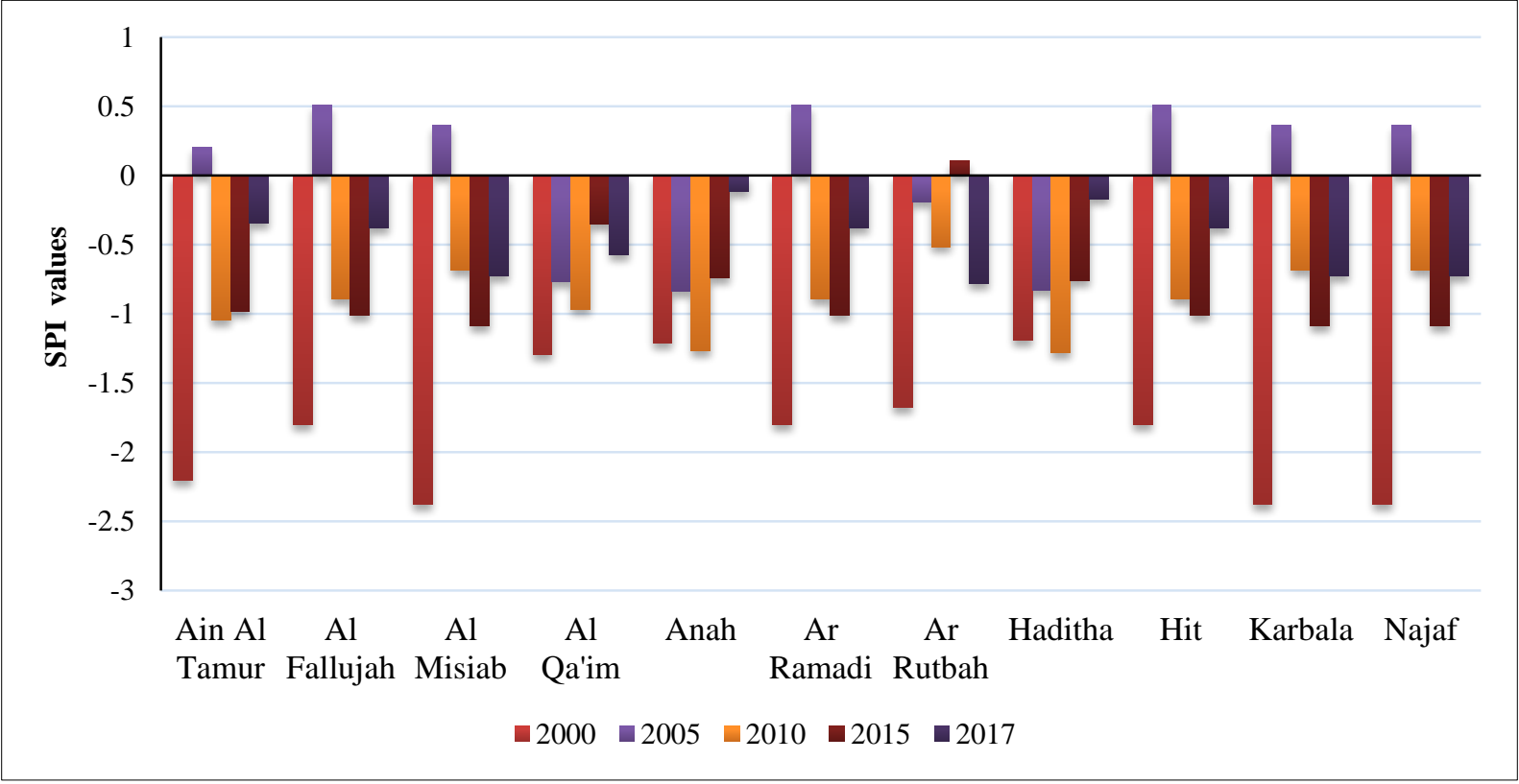

Figure 4. illustrates the SPI values of 11 station for the study period

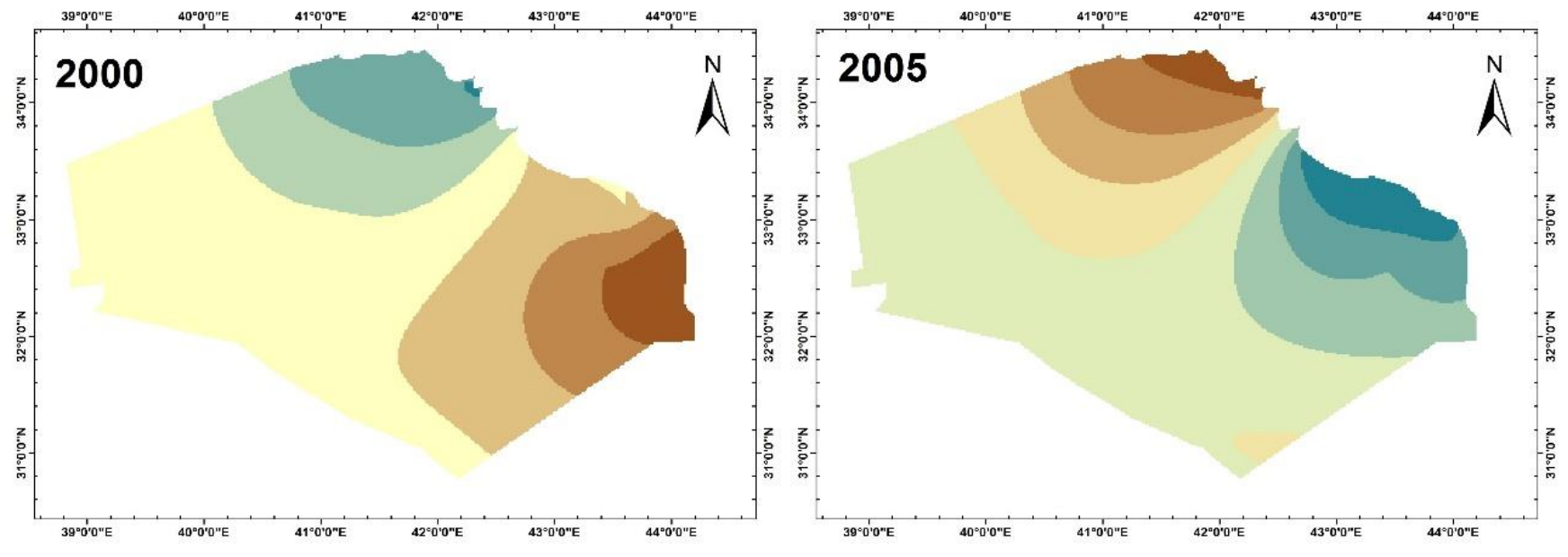



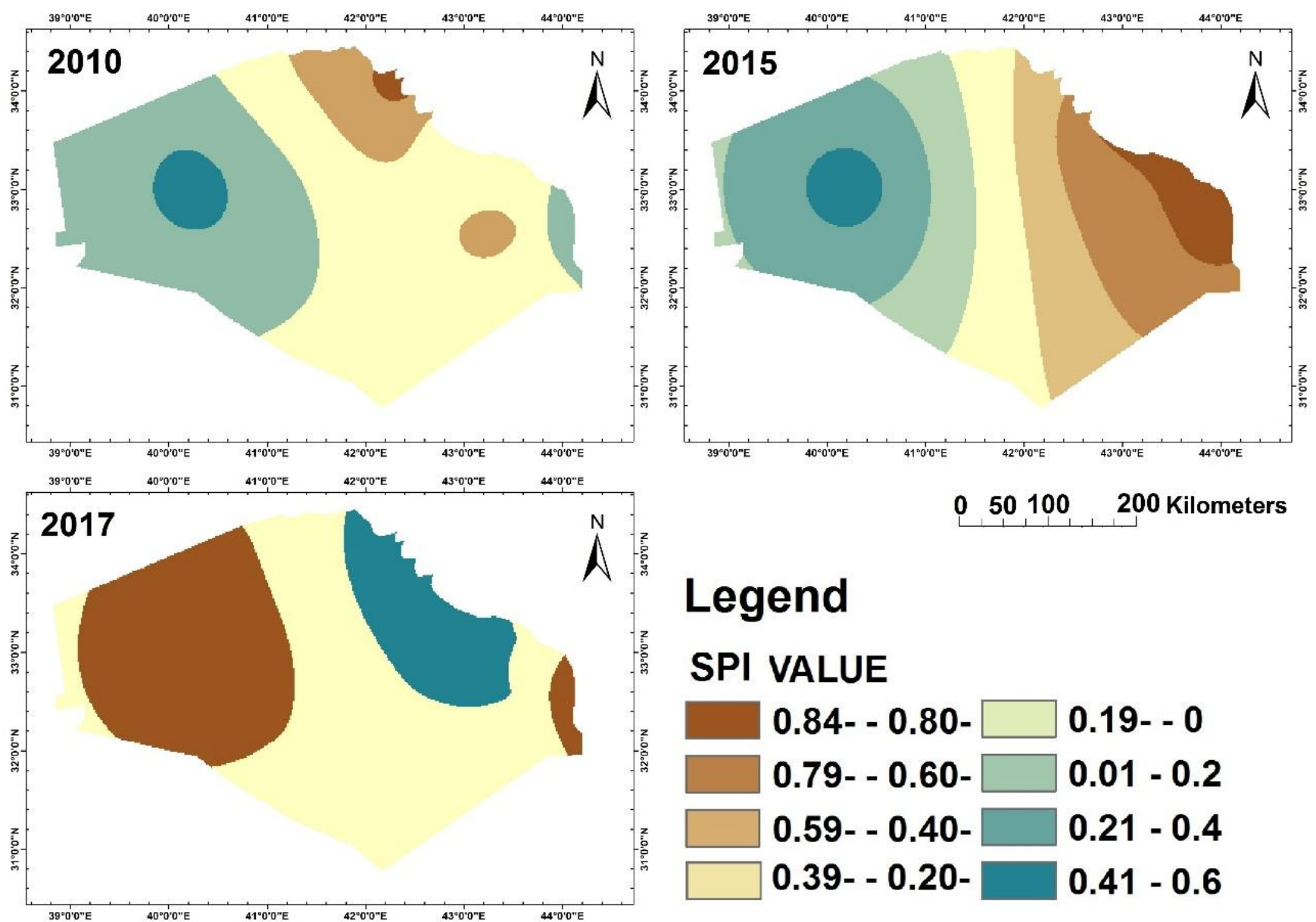

050100200 Kilometers

Legend

SPI VALUE

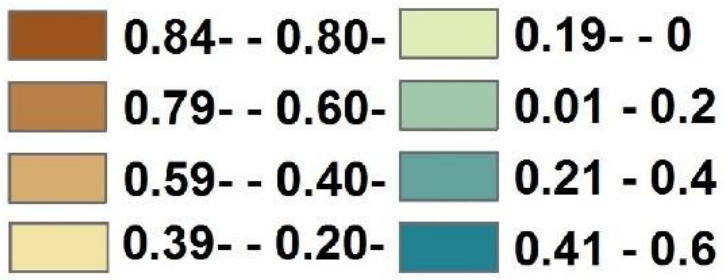

Figure 5. SPI spatial pattern for the study period for 11 stations

\subsection{Precipitation and Drought}

The average annual precipitation rate in Iraq for 16 years of observation (2000-2016) ranged between 200-250 mm [29]. Accordingly, meteorological drought years have been identified in the study area. The meteorological drought years has been categorized depending on the annual precipitation if it is less than $75 \%$ of the average annual precipitation. All the years studied were classified as meteorological drought years (Fig. 6). Accordingly, the North-Eastern part of the region showed lesser dryness during the studied years, due to its proximity to the sedimentary plain region, which has the Semi-Arid climate. The interpretations of the TRMM data revealed that the meteorological drought years were found to be frequently occurring in western Iraq.
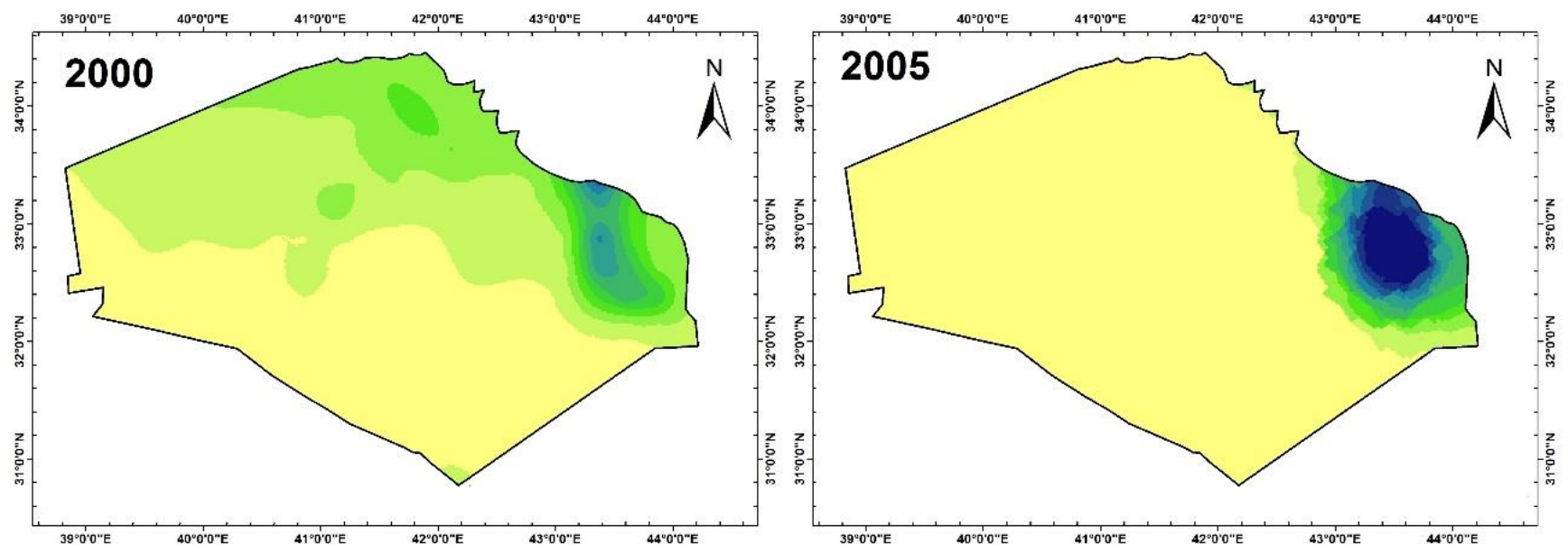

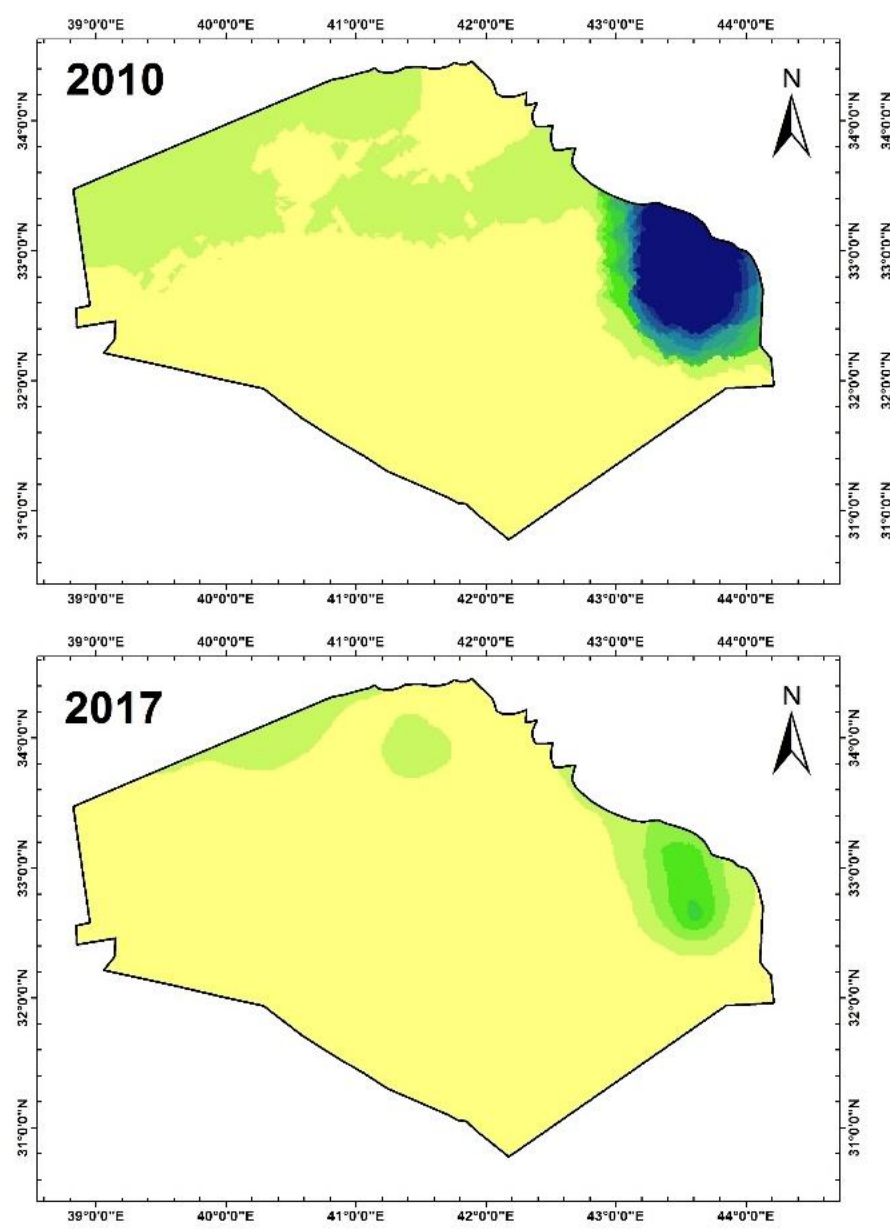

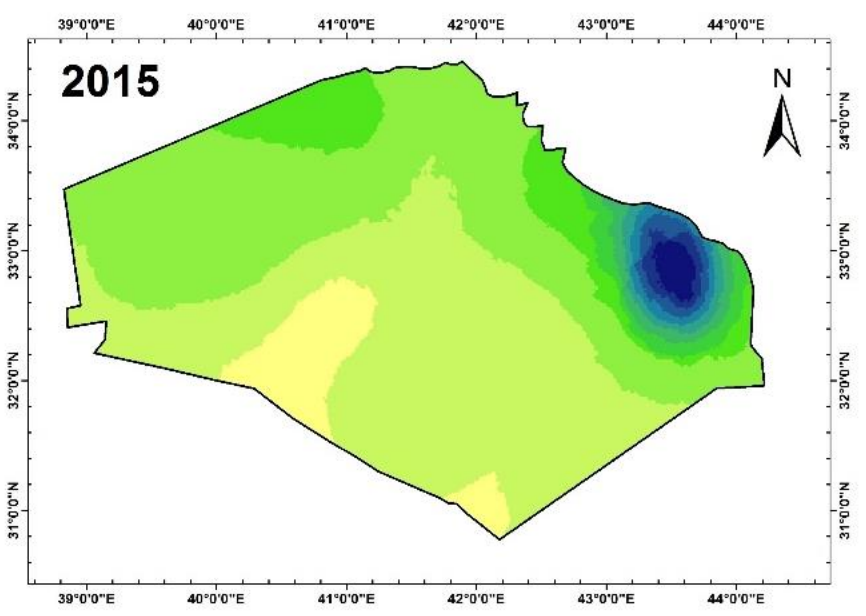

$\begin{array}{lll}0 & 50100 \quad 200 \text { Kilometers }\end{array}$
Legend
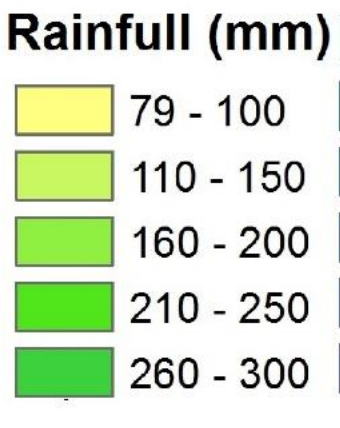

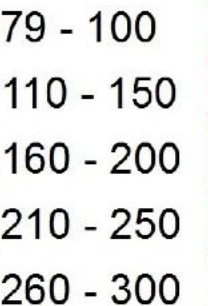

$310-350$

$360-400$

$410-450$

$460-500$

$510-550$

$560-600$

Figure 6. Rainfall Distribution for the study years

\section{Conclusion}

In this study, Tropical Rainfall Measuring Mission (TRMM) was used to monitor the meteorological drought in Western Iraq. Monthly TRMM data was downloaded with spatial resolution of $0.25^{\circ} \times 0.25^{\circ}$. Using TRMM and SPI data, meteorological droughts were identified. ArcGIS coupled with SPI is an effective tool for monitoring drought, SPI index is an effective method that could be used to detect and map the drought, while ArcGIS enhance the results visualization that improves the decision-making process. The results showed that the North-Eastern region had the highest amount of precipitation while the South-Western region showed the lowest precipitation. Additionally, drought and precipitation analysis showed that the droughts were higher than expected in the study areas, mainly in the South and South-West regions. Therefore, an alternate classification is proposed for drought characterization, which classifies the drought type spatially (ultra-high, severe, mild and light). In conclusion, TRMM data could be used as an alternative to the meteorological stations data in local regional studies due to their accuracy, wide coverage and availability.

\section{Conflicts of Interest}

The authors declare no conflict of interest.

\section{References}

[1] Dracup, John A., Kil Seong Lee, and Edwin G. Paulson. "On the Definition of Droughts.” Water Resources Research 16, no. 2 (April 1980): 297-302. doi:10.1029/wr016i002p00297.

[2] Alwan, I. A., Karim, H. H., and Aziz, N. A. "Agro-Climatic Zones (ACZ) Using Climate Satellite Data in Iraq Republic." IOP Conference Series: Materials Science and Engineering. Vol. 518. No. 2. IOP Publishing, 2019. doi:10.1088/1757$899 \mathrm{X} / 518 / 2 / 022034$

[3] Zhang, Lifu, Wenzhe Jiao, Hongming Zhang, Changping Huang, and Qingxi Tong. "Studying Drought Phenomena in the Continental United States in 2011 and 2012 Using Various Drought Indices." Remote Sensing of Environment 190 (March 2017): 96-106. doi:10.1016/j.rse.2016.12.010. 
[4] Elgamal, Amr, Paolo Reggiani, and Andreja Jonoski. "Impact Analysis of Satellite Rainfall Products on Flow Simulations in the Magdalena River Basin, Colombia.” Journal of Hydrology: Regional Studies 9 (February 2017): 85-103. doi:10.1016/j.ejrh.2016.09.001.

[5] Ioannidou, Melina P., John A. Kalogiros, and Adrian K. Stavrakis. "Comparison of the TRMM Precipitation Radar Rainfall Estimation with Ground-Based Disdrometer and Radar Measurements in South Greece.” Atmospheric Research 181 (November 2016): 172-185. doi:10.1016/j.atmosres.2016.06.023.

[6] Sırdaş, S., and Z. Şen. "Meteorological drought modelling and application to Turkey.” Diss. PhD Thesis, Istanbul Technical University, Graduate School of Science, Engineering and Technology, İstanbul, 2002.

[7] McKee, Thomas B., Nolan J. Doesken, and John Kleist. "The relationship of drought frequency and duration to time scales." Proceedings of the 8th Conference on Applied Climatology. Vol. 17. No. 22. Boston, MA: American Meteorological Society, 1993.

[8] Guttman, Nathaniel B. "Accepting the Standardized Precipitation Index: A Calculation Algorithm1." JAWRA Journal of the American Water Resources Association 35, no. 2 (April 1999): 311-322. doi:10.1111/j.1752-1688.1999.tb03592.x.

[9] Bonaccorso, B., Bordi, I., Cancelliere, A., Rossi, G. and Sutera, A. "Spatial variability of drought: an analysis of the SPI in Sicily." Water resources management 17.4 (2003): 273-296.

[10] Moreira, Elsa E., Ana A. Paulo, Luís S. Pereira, and João T. Mexia. “Analysis of SPI Drought Class Transitions Using Loglinear Models.” Journal of Hydrology 331, no. 1-2 (November 2006): 349-359. doi:10.1016/j.jhydrol.2006.05.022.

[11] Tsakiris, G., and H. Vangelis. "Towards a Drought Watch System Based on Spatial SPI.” Water Resources Management 18, no. 1 (February 2004): 1-12. doi:10.1023/b:warm.0000015410.47014.a4.

[12] Yenigun, K. Gümüş, V.,Hakk1 Aydoğdu, M., Yenigün, I. and Ibrahim, W. A "Study on North Iraq Region’s Meteorological Drought: Sulaymaniyah Sampling." Natural Hazards and Disaster Management 04-06 MAY 2018 (ISHAD2018 Sakarya Turkey).

[13] Awchi, Taymoor A., and Maad M. Kalyana. "Meteorological Drought Analysis in Northern Iraq Using SPI and GIS." Sustainable Water Resources Management 3, no. 4 (April 6, 2017): 451-463. doi:10.1007/s40899-017-0111-x.

[14] AL-Timimi, Y. and Osamah A “Comparative study of four meteorological drought indices in Iraq.” IOSR Journal of Applied Physics 8, Issue 5, (2016): 76-84.

[15] Alwan, Imzahim, Abdul Razzak T. Ziboon, and Alaa G. Khalaf. "Comparison of Nine Meteorological Drought Indices Over Middle Euphrates Region During Period from 1988 To 2017.” International Journal of Engineering \& Technology 7, no. 4.20 (November 28, 2018): 602. doi:10.14419/ijet.v7i4.20.27400.

[16] Aziz, N. A., Hasan, R. H. , Abdulrazzaq, Z. T. “Optimum Site Selection for Groundwater Wells Using Integration Between GIS and Hydrogeophysical Data.” Engineering and Technology Journal 36, no. 6A (June 25, 2018). doi:10.30684/etj.36.6a.1.

[17] Hussein, Z. E., Hasan, R. H, Aziz, N. A "Detecting the Changes of AL-Hawizeh Marshland and Surrounding Areas Using GIS and Remote Sensing Techniques.” Association of Arab Universities Journal of Engineering Sciences 25 no.1 (2018): pp. 53-63.

[18] Agbasi, O.E., Aziz, N. A., Abdulrazzaq, Z. T., Etuk, S. E. "Integrated Geophysical Data and GIS Technique to Forecast the Potential Groundwater Locations in Part of South Eastern Nigeria." Iraqi Journal of Science 60, no 5 (June 27, 2019). doi:10.24996/ijs.2019.60.5.11

[19] Mala, Shuchi, Mahesh Kumar Jat, and Parul Pradhan. "An approach to analyze drought occurrences using geospatial techniques." In 15th Esri India User Conference. 2014.

[20] Heim, Richard R. “A Review of Twentieth-Century Drought Indices Used in the United States." Bulletin of the American Meteorological Society 83, no. 8 (August 2002): 1149-1166. doi:10.1175/1520-0477-83.8.1149.

[21] Prasad, A. K., R. P. Singh, V. Tare, and M. Kafatos. "Use of Vegetation Index and Meteorological Parameters for the Prediction of Crop Yield in India." International Journal of Remote Sensing 28, no. 23 (November 20, 2007): 5207-5235. doi:10.1080/01431160601105843.

[22] Sissakian, V. K., and B. S. Mohammed. "Geology of Iraqi Western Desert (Stratigraphy)." Iraqi Bulletin Geol. Min., Special Issue (2007): 51-124.

[23] Hamza, N. M. "Geology of Iraqi western desert; Geomorphology.” Iraqi Bull. Geol. Min., Special Issue (2007): 9-27.

[24] Abdulrazzaq, Zaidoon, Nadia Aziz, and Abdulkareem Mohammed. "Flood Modelling Using Satellite-Based Precipitation Estimates and Digital Elevation Model in Eastern Iraq.” International Journal of Advanced Geosciences 6, no. 1 (January 28, 2018): 72. doi:10.14419/ijag.v6i1.8946. 
[25] Serinaldi, Francesco, Brunella Bonaccorso, Antonino Cancelliere, and Salvatore Grimaldi. "Probabilistic Characterization of Drought Properties through Copulas." Physics and Chemistry of the Earth, Parts A/B/C 34, no. 10-12 (2009): 596-605. doi:10.1016/j.pce.2008.09.004.

[26] NOAA Satellite and Information Services Climate (2010) December, National Climatic Data Center, https://www.ncdc.noaa.gov/sotc/drought/201708

[27] Gulmez, S.P. and Durdu O.F. (2010) Investigating Spatial Distribution of Meteorological Drought in The Buyuk Menderes River Basin Using Standardized Precipitation Index. I. National Symposium on Agricultural Structures and Irrigation, Kahramanmaras, Turkey.

[28] North American Drought (NAD) (2011) A Paleo Perspective, Standard Precipitation Index (SPI), http://www.ncdc.noaa.gov/paleo/drought/drght_spi.html

[29] Abdulrazzaq, Z.T. and Mohammed, A. A. (2017) Using the TRMM Data to Study the Changes of Iso-rainfall Line for Drought Purposes. Proceeding of the First Scientific Conference to Combat Desertification, Baghdad-Iraq. 